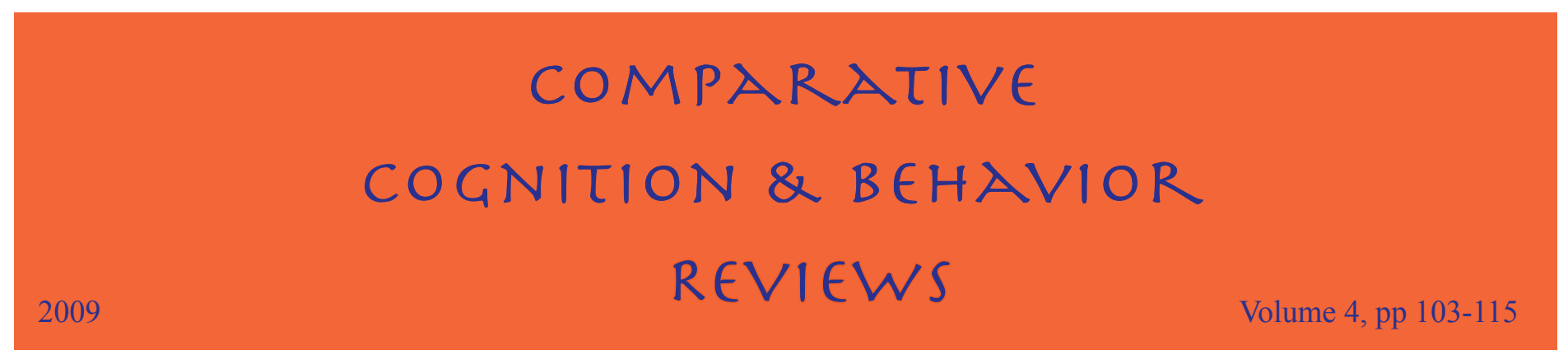

\title{
Why Can Birds Be So Smart? \\ Background, Significance, and Implications of the Revised View of the Avian Brain
}

\author{
Toru Shimizu \\ University of South Florida
}

\begin{abstract}
In the early twentieth century, the anatomical nomenclature of the avian telencephalon (cerebrum) was developed on the basis of flawed assumptions about homology to mammals. The classic terminology implied that the majority of the avian telencephalon was basically composed of nuclei forming massive basal ganglia which controlled only simple, unlearned behavior. Later research revealed that this assumption was inaccurate and that the avian telencephalon contains a welldeveloped pallium in addition to basal ganglia. The avian pallium is equivalent to specific mammalian counterparts (e.g., neocortex, claustrum, and/or amygdala) that are responsible for complex and sophisticated behavior. In 2002, based on a revised interpretation of the avian brain organization, the new nomenclature was proposed by comparative neuroscientists who participated in the Avian Brain Nomenclature Forum. This paper presents the general background and significance of the revised view of the avian brain, as well as implications for understanding the remarkable cognitive abilities of birds.
\end{abstract}

Avian brain research was started by a handful of comparative neuroanatomists in the early twentieth century. From a relatively small field with a limited audience, it has evolved into a major biological field supported by a large sum of research money. Many scientists are involved in avian research, not only to study birds for intrinsic reasons, but also to use the avian brain as a model to investigate general principles of the nervous system with regard to behavior, development, anatomy, physiology, and molecular biology (e.g., Nottebohm, 2002; Thanos \& Mey, 2001; Zeigler \& Bischof, 1993;

Toru Shimizu, Department of Psychology, University of South Florida.

I am grateful to the participants of the Avian Brain Nomenclature Forum in 2002 for their efforts, with particular gratitude to Erich Jarvis and Anton Reiner for their leadership in this endeavor. I am also grateful to Tadd B. Patton, Frank Fishburn, Verner P. Bingman, and two anonymous reviewers for their valuable comments on the manuscript. The title of this paper was inspired by Karin Isler and Carel P. Van Schaik's article "Why are there so few smart mammals (but so many smart birds)?" (Biology Letters, 2009, 5, 125-129).

Correspondence concerning this article should be addressed to Toru Shimizu, PCD 4118G, University of South Florida, 4202 E. Fowler Avenue, Tampa, FL 33620-7200, U.S.A. E-mail: shimizu@cas.usf.edu
Zeigler \& Marler, 2008). In particular, as data accumulate to reveal the remarkable cognitive proficiencies of birds proficiencies that were traditionally considered to be the sole province of the mammalian brain - avian models now play a major role in studies about the neural mechanisms underlying various cognitive functions, such as learning, memory, attention, and consciousness (e.g., Bingman \& Able, 2002; Butler \& Cortterill, 2006; Doupe \& Kuhl, 1999; Watanabe \& Hofman, 2008). Therefore, it is essential that scientists in avian and mammalian research communities can easily exchange information about their discoveries and readily understand the significance of their respective findings.

In the past, scientific communication between the avian and mammalian research communities was not easy. One substantive obstacle was the confusing terminology used to describe some critical structures in the avian brain (Jarvis et al., 2005; Reiner et al., 2004). The terminology was adopted about 100 years ago by the pioneers of comparative neuroanatomy based on the classic view of vertebrate brain evolution and flawed assumptions about homology to mammals. Later studies revealed that the classic view was fundamentally false and that the terminology was inaccurate and misleading. Although avian brain researchers realized these mistakes in the mid-twentieth century, no changes were made in the nomenclature until the twenty-first century. 
In July 2002, after two years of preparation, a group of comparative neuroscientists gathered for an international forum held at Duke University in North Carolina. The purpose of the forum was to abandon the old nomenclature of certain brain structures and to develop new and more accurate names for the avian brain. The participants included experts on the avian brain, as well as others who are specialized for mammals, reptiles, and other vertebrates. The forum included presentations of various hypotheses about brain evolution and proposals for possible new name options. After three days of intensive discussion, the participants adopted the new nomenclature. It was welcomed and accepted in the scientific community and sparked renewed interests among avian and mammalian brain researchers alike.

This paper first presents the classic interpretation of the evolution of the vertebrate brain and the old avian nomenclature based on the classic view. The updated modern interpretation of brain evolution is then introduced with the new nomenclature. Also discussed are the implications of the modern view for understanding the cognitive abilities of birds. Throughout the paper the question and answer format is used to facilitate accessibility to issues of individual interest. For the same reason, limited anatomical terms and jargon are presented only when necessary and in-depth discussion about minor issues is avoided. More detailed information about the 2002 Forum and the anatomical significance of the new nomenclature are presented elsewhere (Jarvis et al., 2005; Reiner et al., 2004).

\section{The Classic View of the Avian Brain}

\section{Who developed the classic view and the old nomenclature?}

The old nomenclature was developed by early comparative neuroanatomists about 100 years ago. At the end of the nineteenth century and the beginning of the twentieth century, new histological techniques were developed, such as staining methods for nervous tissues by German pathologist Franz Nissl (1860 - 1919) and Italian physician Camillo Golgi (1843 - 1926). The new methods allowed early researchers to observe detailed images of nerve cells and fibers for the first time in history. Ludwig Edinger (1855 - 1918) in Germany was one of the first researchers to use these techniques. Other pioneers, such as J. B. Johnston, G. C. Huber, E. C. Crosby, C. U. Ariëns Kappers, and C. J. Herrick, also began to study and compare the brains of a variety of animals, including different fishes, amphibians, reptiles, birds, and mammals.

Anatomical examinations with the new techniques led early neuroanatomists to formulate the classic view of vertebrate brain evolution, in which the brain expanded from an underdeveloped form of "lower" animal to a more advanced form of "higher" animal. The avian brain was believed to be a more primitive brain compared to the well-developed, advanced mammalian brain. The avian telencephalic structures were named in accordance with this classic view. Edinger and his students (Edinger, 1908; Edinger, Wallenberg, $\&$ Holmes, 1903) proposed the original names which were later modified by Ariëns Kappers and his colleagues (Ariëns Kappers, Huber, \& Crosby, 1936).

The old nomenclature by Ariëns Kappers et al. was maintained in the influential stereotaxic atlas of the pigeon brain by Harvey J. Karten and William Hodos (1967). Despite the fact that Karten and Hodos disproved the classic view of the vertebrate brain evolution, they believed that the benefit of continuing to use the familiar old nomenclature (with a few exceptions) outweighed the possibility of making changes that could cause confusion. Subsequent atlases for other avian species essentially followed the terminology used in the Karten and Hodos atlas (e.g., Kuenzel \& Masson, 1988; Stokes et al., 1974).

\section{What were the most significant aspects of the classic view and the old nomenclature?}

No avian brains are alike just as no mammalian brains are exactly the same. There are considerable variations in the development of different brain structures within birds. Nevertheless, the fundamental design of the avian brain is consistent among all birds. As in other vertebrates, the bird brain consists of the hindbrain, midbrain, and forebrain (thalamus and telencephalon). The classic view of the bird brain asserted that the avian hindbrain, midbrain, and thalamus were highly homologous to those same regions in mammals, but not the telencephalon. As shown in Figure 1, the basic organization of the mammalian telencephalon consists of a group of nuclei forming basal ganglia (e.g., dorsal striatum and globus pallidus) at the telencephalic floor and a pallium ("cloak" in Latin; e.g., neocortex and hippocampus) at the mantle of the telencephalon enveloping the basal ganglia. The central notion of the classic view stated that the avian and mammalian telencephalons were fundamentally different with the belief that the avian telencephalon essentially consisted of gigantic basal ganglia and a meager pallium, as depicted in Figure 2A.

It is perhaps useful to clarify the term homology at this point. Homology is a central concept used to describe the evolutionary relationship between traits found in different animals. The term indicates that certain traits in different species can be evolutionally traced back to those of their common ancestor, regardless of appearance or function. The classic view implied that the major part of the avian telencephalon was homologous to the mammalian basal ganglia - meaning that both structures presumably evolved from the same basal ganglia region of their common ancestor (which is called the stem amniote). 


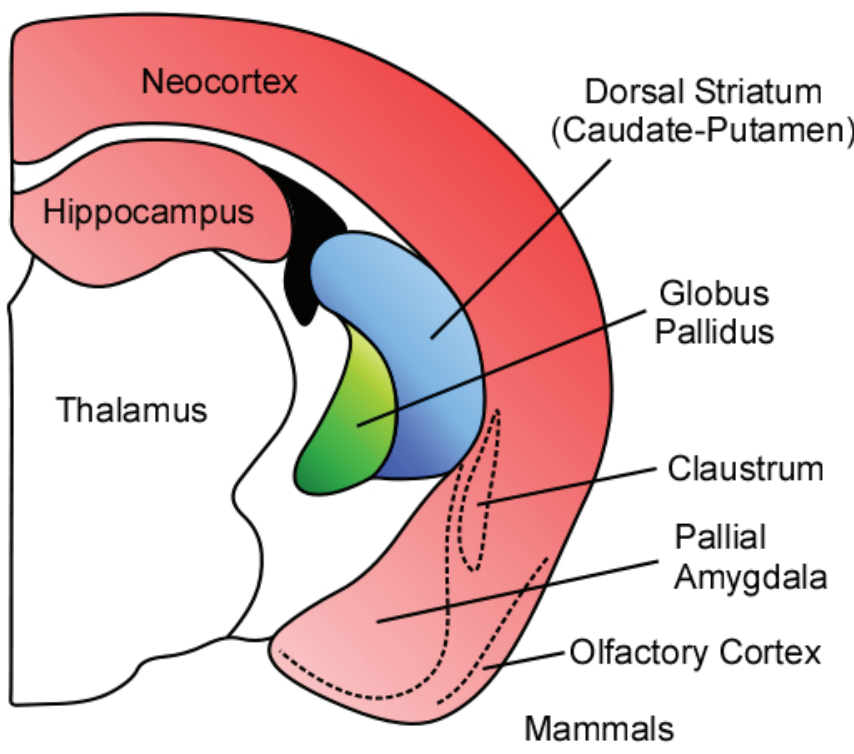

Figure 1. A schematic figure showing a transverse telencephalic section of the right hemisphere of the rat. The red portion represents the pallium; the blue portion represents the striatal part of the basal ganglia; the green portion represents the pallidal part of the basal ganglia; and the black portion represents the lateral ventricle. Note. From Figure 1, "Revised nomenclature for avian telencephalon and some related brainstem nuclei," by A. Reiner et al., Journal of Comparative Neurology, 2004, 473, p. 380. Copyright 2004 by the John Wiley \& Sons, Inc. Adapted with permission.

The avian telencephalon contains anatomically distinct subdivisions. In the old nomenclature, many of these subdivisions were suffixed with the term "striatum" to indicate that these structures were part of the basal ganglia (Fig. 2A). The striatum is the term used to describe the striated appearance of a large part (caudate-putamen) of the mammalian basal ganglia because of the fiber bundles passing through this region. Since the avian "striatal" structures do not appear to be striated, the old nomenclature was obviously based on inferred homology with the mammalian basal ganglia, not based on the histological features of the avian telencephalon.

\section{Why did early neuroanatomists believe that the avian tel- encephalon comprised massive basal ganglia?}

There are two main reasons that early neuroanatomists named the avian telencephalic structures after the mammalian basal ganglia "striatum." One is the theoretical influence of the Aristotelian concept of phylogenetic scale, scala naturae, and the other is the cytoarchitectonic characteristics of the avian telencephalon.

Theoretical reason: The thinking of early neuroanatomists was greatly biased by the scala naturae-based concept, which holds that living animals are ranked in a continuous ascending order from "lower, primitive, less evolved" animals to "higher, advanced, more evolved" animals. The ascending order would lead from fishes to amphibians, to reptiles, to birds, to mammals, to primates, and finally to humans at the pinnacle. When Charles Darwin introduced his idea of evolution, early neuroanatomists interpreted this to mean that the brain evolution of vertebrates also occurred as a unilinear or unidimensional process from a simple form to a complex advanced form through the evolutionary ladder. They proposed a type of accretionary theory, in which they believed that brains evolved from a primitive brain to a complex one by adding "new" parts on top of the "old" parts. The "old" brain was called the palaeoencephalon, which basically corresponded to the basal ganglia or striatum at the base of the telencephalon. The "new" brain was termed the neoencephalon, which corresponded to the pallium or cortex at the top of the telencephalon. In this view, the "old" brain could control only reflexive and instinctual behavior whereas the "new" brain could produce more advanced, learned, and complex behavior.

Anatomical reason: The majority of the avian telencephalon consists of nuclear grey matter which appears similar to the mammalian basal ganglia. In these nuclear masses, neurons are not organized in a laminar fashion, but aggregated as distinct clusters or nuclei. In mammals, such nuclear masses (basal ganglia) are surrounded by a thin and large sheet of nerve cells (cerebral cortex), where neurons are arranged parallel to the surface as layers or laminae. No such large laminated neural architecture is apparent in the avian and other non-mammalian brains, a fact that led to the assumption that a developed cerebral cortex is a unique characteristic of the mammalian telencephalon.

Another similarity of the avian telencephalon with the mammalian basal ganglia is the topographical location of these nuclear masses in the brain. The nuclear mass of the avian telencephalon is ventrolateral to the lateral ventricle just as the mammalian basal ganglia are positioned to this ventricle. The relationship of the nuclear masses relative to the lateral ventricle can be seen in transverse brain sections (Figs. 1, 2).

\section{How was the classic view reflected in the old nomencla- ture?}

In the original nomenclature, there were four major "striatal" regions in the avian telencephalon: paleostriatum, archistriatum, neostriatum, and hyperstriatum. The prefixes "paleo-", "archi-", and "neo-" were used to indicate the inferred evolutionary order of the emergence of these structures. According to the classic view, the oldest part of the avian telencephalon was the paleostriatum; then the archistriatum and the neostriatum evolved; and finally the hyperstriatum 


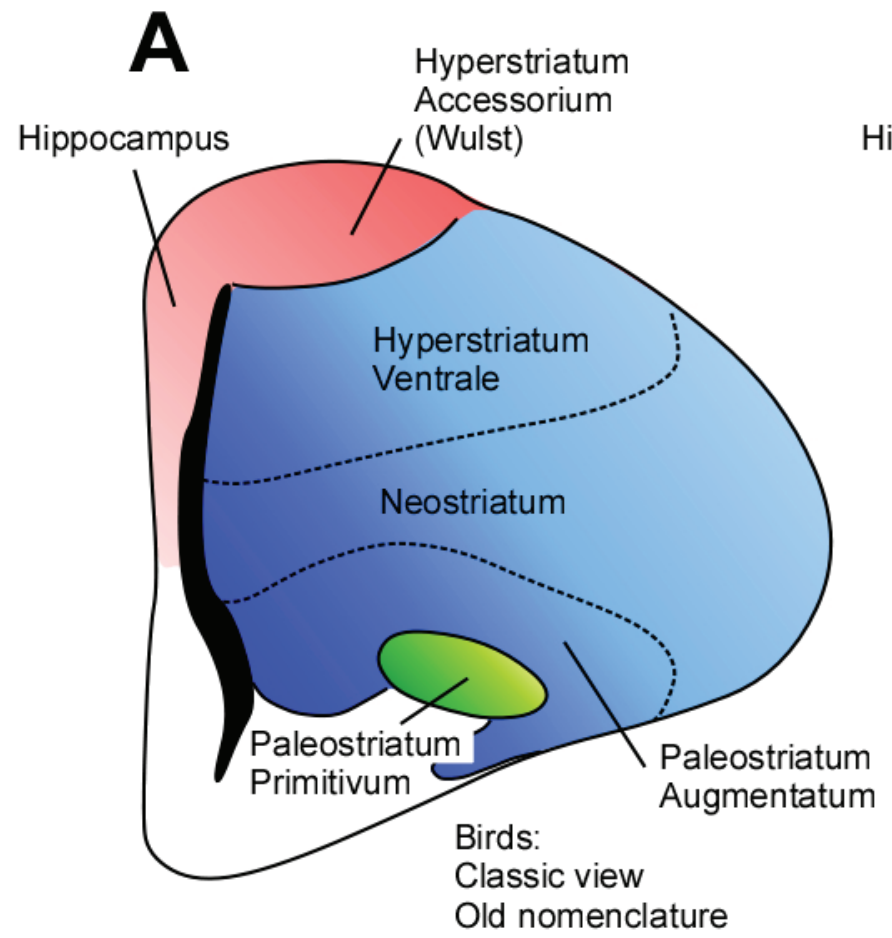

B

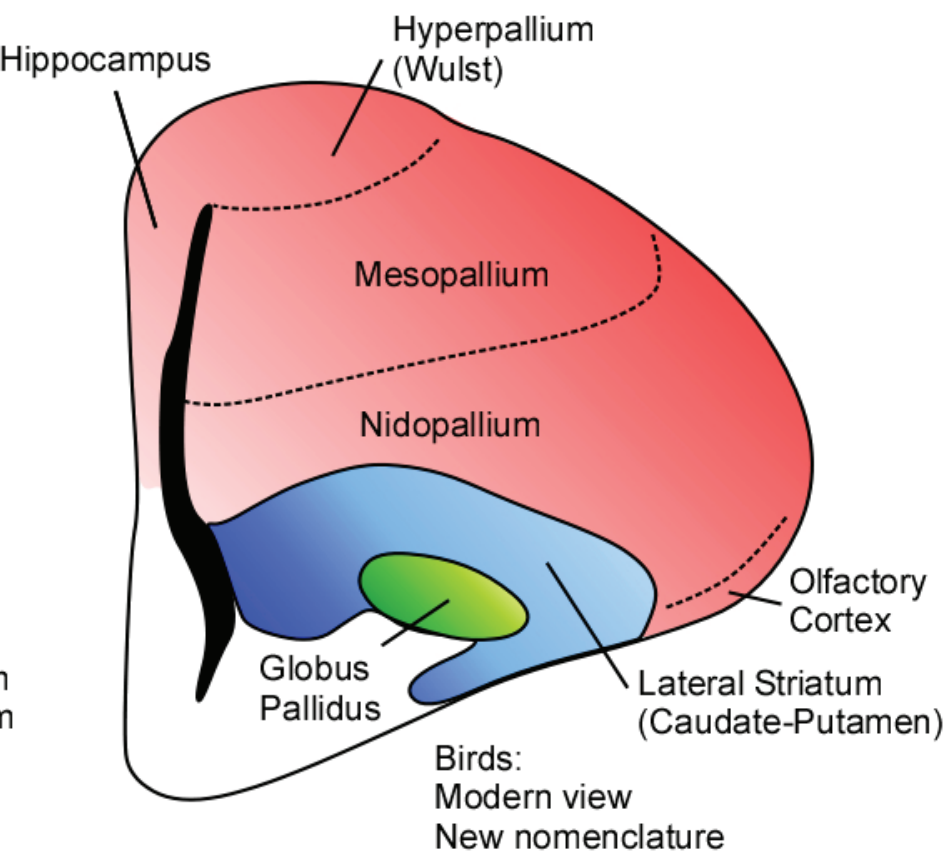

Figure 2. Schematic figures showing transverse telencephalic sections of the right hemispheres of the pigeon according to the classic interpretation (A) and the modern interpretation (B). The red portions represent the pallium; the blue portions represent the striatal parts of the basal ganglia; the green portions represent the pallidal parts of the basal ganglia; and the black portions represent the lateral ventricles. Subdivisions in the avian telencephalon are identified using (A) the old nomenclature (Ariëns Kappers et al., 1936; Karten \& Hodos, 1969) and (B) the new nomenclature adopted by the Avian Brain Nomenclature Forum in 2002 (Jarvis et al., 2005; Reiner et al., 2004). Note. From Figure 1, "Revised nomenclature for avian telencephalon and some related brainstem nuclei," by A. Reiner et al., Journal of Comparative Neurology, 2004, 473, p. 380. Copyright 2004 by the John Wiley \& Sons, Inc. Adapted with permission.

emerged, which was considered to be the newest portion. As Figure 2A shows, each "striatal" subdivision was further divided into more subregions based on cytoarchitecture.

Paleostriatum: In the classic view, the paleostriatum ("oldest" striatum) was found in all vertebrates including fishes. The fish paleostriatum was named the primitivum (old part) and was believed to correspond to the mammalian globus pallidus (a part of the basal ganglia). In reptiles and birds, the paleostriatum developed further and differentiated into two parts by adding an augmentatum region above the primitivum.

Archistriatum: As amphibians evolved from fishes, the archistriatum ("old" striatum) emerged. It was positioned above the paleostriatum, and was proposed to be a primitive amygdala. This nucleus was located most caudally in the avian telencephalon and therefore it is not included in Figure $2 \mathrm{~A}$.

Neostriatum: A "new" part above the paleostriatum and archistriatum was called the neostriatum, which was not present in fishes, but was found in amphibians and expanded significantly in reptiles and birds. The neostriatum was considered to correspond to the caudate-putamen part of the mammalian basal ganglia. Although not shown in Figure
$2 \mathrm{~A}$, the neostriatum was further divided into three regions along the anterior-posterior axis: the neostriatum frontale, intermediale, and caudale. Later studies revealed that several distinct sensory-specific nuclei were embedded in the neostriatum, most notably the visual ectostriatum and auditory Field L (Karten, 1969). The presence of the sensory nuclei was a compelling observation that the avian neostriatum was more than simply basal ganglia.

Hyperstriatum: The hyperstriatum ("hypertrophied" striatum) was believed to be an overgrown striatum, which existed only in birds, but no other animals. It was divided into several subregions including a ventrally located ventrale and a dorsally located accessorium. The hyperstriatum ventrale is nuclear, as are most "striatal" structures. Despite the "striatal" name, the hyperstriatum accessorium was regarded as a pallial structure by early neuroanatomists. This region has a laminated neural organization, although it is not six-layered like the mammalian neocortex. Edinger and his colleagues (1903) named this part the 'cortex frontalis' and it was later renamed as the hyperstriatum accessorium by Ariëns Kappers et al. (1936). It was (and is) also called the wulst (from a German word for "bump") because it is an elevation on the most dorsal surface of the telencephalon. 
How did the classic view explain the cognitive abilities of birds?

Only limited information about animal cognition was available in the late nineteenth century and early twentieth century with often excessively anthropomorphistic, unreliable anecdotes (Romanes, 1882). Due to the lack of scientific data, early neuroanatomists (Ariëns Kappers et al., 1936; Edinger, 1908; Edinger et al., 1903; Herrick, 1956) and comparative biologists (Lloyd Morgan, 1894) considerably underestimated the cognitive abilities of non-mammals. Ironically, the misconception about animal behavior and cognition was somewhat consistent with the classic view of brain evolution. Early scientists believed that mammals were capable of complex and intelligent behavior because only mammals had a well-developed pallium. According to the classic view, the pallial region of mammals evolved to expand in size and complexity and eventually resulted in an elaborated six-layered neocortex, the newest and thus most advanced brain structure. In contrast, birds, as well as other non-mammals, were presumed to be controlled by reflexes and instincts because their brains consisted of primarily basal ganglia and a diminutive pallium.

\section{The Modern View of the Avian Brain}

\section{Who developed the modern view and the new nomencla- ture?}

In the mid-twentieth century, comparative neuroscientists including Karten and Hodos started to realize that the classic view of the avian brain was inaccurate and that the old nomenclature was misleading (e.g., Karten, 1969; Karten \& Hodos, 1967). Gradually the modern interpretation of the avian brain was developed in the updated framework of vertebrate brain evolution. Despite this major shift in thinking, these scientists kept using the old nomenclature until the early twenty-first century, because the old nomenclature had been entrenched in avian research for many decades. Some researchers wanted to maintain the same nomenclature for consistency. Others, who were more open to name changes, could not reach a consensus on alternative terminology because there were various possible term options based on different hypotheses about the organization of the avian brain. The new nomenclature was finally developed by the Avian Brain Nomenclature Forum in 2002 (Jarvis et al., 2005; Reiner et al., 2004). The participants included 28 comparative neuroscientists, representing multidisciplinary expertise, who are respected leaders in their research fields. The names of the participants are available as the authors of the two official papers (Jarvis et al., 2005; Reiner et al., 2004). Among them, the key players were Erich D. Jarvis at Duke
University, who envisioned the value of such a forum and was the main organizer, and Anton Reiner at the University of Tennessee, Memphis, who was the forerunner in this endeavor, having worked on the nomenclature issue since the late 1990's. In addition, many other scientists participated in preparatory discussions through e-mail communications during the two years prior to the Forum. Today, the new nomenclature that was proposed by the 2002 Forum is generally well-accepted in the scientific community, including avian researchers who did not participate in the Forum. The official nomenclature papers (Jarvis et al., 2005; Reiner et al., 2004) have been cited over 400 times since they were published.

\section{What are the most significant aspects of the modern view and the new nomenclature?}

Based on updated data, the modern view of vertebrate brain evolution refutes the classic view. In the new interpretation, all vertebrates share the same basic design of telencephalic organization, which consists of both a pallium and basal ganglia. The pallium of non-mammals like birds was mistaken to be a part of the basal ganglia because it did not show the same neural architecture (i.e., a laminar arrangement) as the mammalian pallium - a six-layered neocortex. This means that the avian telencephalon is not simply hypertrophied basal ganglia. Of all the "striatal" structures in the old nomenclature, only a small portion (i.e., "paleostriatum") is homologous to the mammalian basal ganglia. The remaining "striatal" parts derive from the pallial region of the developing telencephalon despite their non-laminated appearance. As shown in Figure 2B, about $75 \%$ of the entire telencephalic volume is now considered to be pallial (Jarvis et al., 2005).

The revision of the terminology became necessary because, by the end of the twentieth century, misconceptions about the bird brain due to the old terminology became too prevalent and common in the mammalian research community. In past research papers, it was not unusual to find mammalian researchers who incorrectly compared the whole avian telencephalon to the mammalian basal ganglia and who falsely assumed that birds without an enlarged, developed pallium were deficient in sophisticated neural computation and cognitive abilities. Although avian research flourished in many biological and psychological fields, the old nomenclature often impeded an easy exchange of information between avian and mammalian researchers.

During the 2002 Forum, terms were selected to represent the updated understanding of the avian brain and the correct homologies with the mammalian brain. The suffix "striatum" was removed from many telencephalic structures that were discovered to be pallial in nature. These structures were renamed with the suffix "pallium." The prefixes that 
made inaccurate references to the evolutionary relationship of structures ("paleo-", "archi-", "neo-") were also eliminated.

\section{Why do contemporary neuroscientists conclude that the classic view is false?}

Up until the mid-twentieth century, the classic view of the evolution of the vertebrate brain widely prevailed. Although there were early researchers who voiced their dissenting opinions against the classic view (Holmgren, 1925; Källén, 1953; Kuhlenbeck, 1938; Rose, 1914), their views were not predominant. Eventually, later researchers were able to refute the classic view based on three lines of compelling arguments: 1) theoretical, 2) anatomical, and 3) behavioral evidence.

Theoretical evidence: The first reason is the updated understanding of vertebrate evolution. Comparative neuroscientists accepted the revised and accurate view of vertebrate brain evolution based on analyses of fossil records and comparative phyletic studies. Instead of a unilinear or unidimensional process, evolution is characterized by divergence and multi-linearity (Butler \& Hodos, 2005; Campbell \& Hodos, 1991; Hodos \& Campbell, 1969; Northcutt, 1981).

These characteristics are seen in Figure 3, illustrating the currently accepted evolutionary relationships among tetrapods (amphibians, reptiles, birds, and mammals) (Carroll, 1988). Briefly, ancestral tetrapods diverged from one group of bony fish in the Devonian period about 400 million years ago (MYA). Tetrapods then gave rise to stem amniotes, which further diverged into two major amniote groups by the end of the Carboniferous period. They were synapsids and diapsids, the ancestors of mammals and birds respectively. Synapsids comprise two successive orders, pelycosaurs and then therapsids. From the latter, early mammals arose in the Late Triassic period more than 200 MYA. Diapsids became the ancestors of the majority of living reptiles. The lineage of diapsids diverged several times to produce multiple groups, including dinosaurs, which were the most successful vertebrates for more than 150 million years, beginning in the Later Triassic period to the end of the Cretaceous period. Birds arose most likely 140 MYA from the saurichian dinosaurs in the Late Jurassic period.

Hence, unlike birds, mammals did not evolve from ancestral reptiles. The ancestors of mammals (synapsids) were stem amniotes, which were also the ancestors of reptiles and birds. The lineages leading to mammals and birds are separate since synapsids and diapsids diverged from stem amniotes about 300 MYA. This means that each of the avian and mammalian brains has an independent evolutionary history of millions of years. The avian and reptilian brains are not primitive, undeveloped versions of the mammalian brain.

Anatomical evidence: The second reason that the classic view is considered false is that new anatomical information became available due to methodological development in neurochemistry, hodology (the study of neural connections), and molecular biology. For instance, using new histochemical techniques, the distribution of dopamine was analyzed to compare mammals and birds (Jurio \& Vogt, 1967). In the mammalian basal ganglia, dopamine is abundant in the caudate-putamen (striatum) compared to the cerebral cortex. If the majority of the avian telencephalon was a striatum - as the classic view suggested - dopamine should be found in all the "striatal" regions in the avian telencephalon. Research shows that only a small part of the telencephalon (the paleostriatum augmentatum) contains a high level of dopamine. Similar results were obtained regarding the distributions of other neurochemicals (e.g., acetylcholinesterase, substance $\mathrm{P}$, and enkephalin) to conclude that only the paleostriatum augmentatum is equivalent to the mammalian caudate-putamen and that the paleostriatum primitivum corresponds to the globus pallidus (Karten, 1969; Reiner, Medina, \& Veenman, 1998). The conclusion is reinforced by hodological and molecular evidence. Tract-tracing studies revealed that the connection patterns of the paleostriatum with other brain structures (e.g., midbrain and hindbrain) are similar to those of the mammalian basal ganglia (Brauth \& Kitt 1980; Karten \& Dubbeldam, 1973; Reiner, Brauth, \& Karten, 1984). Embryonic molecular studies supported the same conclusion that the avian paleostriatum is homologous to the mammalian basal ganglia in terms of the expression of certain genes (Marin \& Rubinstein, 2001; Puelles et al., 2000).

Behavioral evidence: The classic view presumed that nonmammals like birds could only perform unlearned, instinctual behavior because the majority of their telencephalon was striatal. In this view, birds with a relatively small pallium were not able to behave like mammals that could enjoy complex and sophisticated behavior owing to the presence of a large neocortex. For the past 50 years, a new picture about the cognitive abilities of birds has emerged using scientifically rigorous methods (Wasserman \& Zentall, 2006). Some of the complex behaviors of birds are considered to be comparable to those of primates (Emery, 2006). Pigeons can memorize and discriminate more than 700 photographs (Cook, Levison, Gillett, \& Blaisdell, 2005) and discriminate between the paintings of cubistic and impressionistic styles of painting (Watanabe, Sakamoto, \& Wakita, 1995). Songbirds, parrots, and hummingbirds show the abilities of complicated vocal learning (Doupe \& Kuhl, 1999; Jarvis et al., 2000; Pepperberg, 1999). Starlings can be trained to acquire recursion grammar which had been considered to be unique to human language (Gentner, Fenn, Margoliash, \& Nusbaum, 2006). New Caledonian crows manufacture hook-tools with their bills and use them to search for prey in holes in tree trunks (Hunt, 1996). Scrub-jays appear to form episodic-like memory about a previous experience (Clayton 


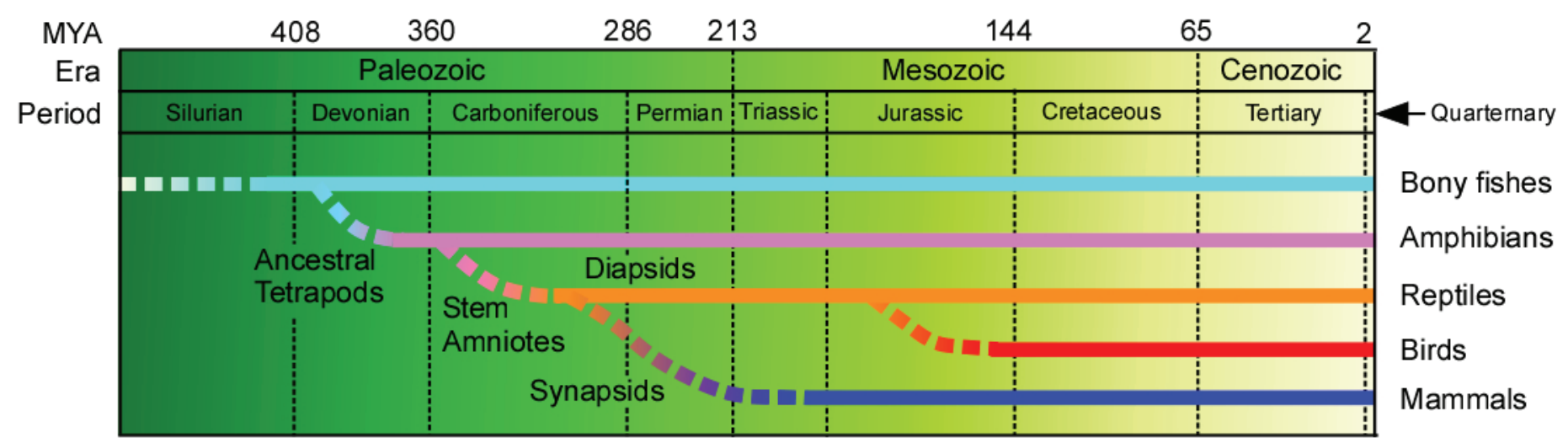

Figure 3. Probable phylogenetical relationships of bony fishes, amphibians, reptiles, birds, and mammals. MYA: million years ago. Note. From Figure 2, “Avian brains and a new understanding of vertebrate brain evolution," by E.D. Jarvis et al., Nature Reviews Neuroscience, 2005, 6, p. 156. Copyright 2005 by Nature Publishing Group. Adapted with permission.

\& Dickinson, 1998), upon which they can behave as if they have predictions for the future (Clayton, Bussey, \& Dickinson, 2003).

\section{What are the major changes in the nomenclature?}

During the 2002 Forum, new names were adopted for over 30 brain areas. The majority of changes were made for the telencephalic structures. Figure 2B represents the main changes in the nomenclature for the telencephalon.

Paleostriatum - Lateral Striatum and Globus Pallidus: The avian paleostriatum augmentatum and primitivum were renamed as the lateral striatum and globus pallidus, respectively. The avian lateral striatum is considered to be equivalent to the mammalian dorsal striatum (caudate-putamen), whereas the avian globus pallidus corresponds to the mammalian counterpart with the same name.

Archistriatum - Amygdala and Arcopallium: The archistriatum became the arcopallium (arched pallium). Parts of the archistriatum were also renamed as the amygdala to indicate that they belong to the amygdaloid complex.

Neostriatum - Nidopallium: The neostriatum became the nidopallium. The term "nido-" means a nest, which implies that this structure contains several anatomically distinct and functionally different nuclei, such as the visual ectostriatum and the auditory Field L. The ectostriatum was renamed as the entopallium and Field L maintained the same name.

Hyperstriatum - Mesopallium and Hyperpallium: In the hyperstriatum, the accessorium was renamed as the hyperpallium (hypertrophied pallium) whereas the ventrale became the mesopallium (middle pallium). The hyperpallium and mesopallium obtained different names because they are distinguishable cytologically, chemically, hodologically, functionally, and developmentally. The hyperpallium was regarded as pallial by early neuroanatomists and this interpretation was supported by the 2002 Forum participants. It is believed to be homologous to part of the mammalian neocortex.

Dorsal Ventricular Ridge: The nidopallium, arcopallium, and the mesopallium are together designated as the dorsal ventricular ridge (DVR), a voluminous nuclear mass protruding into the lateral ventricle (Ulinski, 1983). Although the origin of the DVR was proposed to be striatal (i.e., basal ganglia) in the classic view, it is now considered to be pallial. The DVR is also found in reptiles, yet the reptilian DVR is not as enlarged or as differentiated as the avian one.

Brainstem: At least nine structures in the brainstem obtained new names based on the updated information. For example, one of the brainstem structures is a cell group traditionally called the nucleus tegmenti pedunculo-pontinus, pars compacta (TPc) in the midbrain (Karten \& Hodos, 1967). The TPc name was based on the location and density of the cell group because there was then no other information about the nucleus. Later anatomical, chemical, and physiological investigations revealed that TPc is directly comparable to the substantia nigra pars compacta ( $\mathrm{SNc}$ ) of mammals. Most notably, just like SNc, TPc sends major dopaminergic projections to the avian counterpart of the striatal region of the basal ganglia (Kitt \& Brauth, 1986a, b; Reiner et al., 2004). The participants of the 2002 Forum decided that the common name SNc should be adopted to clarify the homologous relationship between these nuclei.

\section{Why is the nuclear pallium (DVR) categorized as a pallium despite its non-laminar organization?}

In mammals, the term pallium is often used synonymously with a six-layered neocortex. Although the neocortex is the largest structure derived from the pallial sector of the developing telencephalon, the pallium cannot be solely defined as a six-layered laminar configuration. There are other pallial structures in the mammalian brain that are laminated with 
fewer than six layers, and still others that are not laminated at all. Both the olfactory (piriform) cortex and hippocampus have pallial origins, and are laminated with two to three layers (Fig. 1). Recent studies showed that nuclear (nonlaminar) structures like the claustrum and lateral parts of the amygdala (Fig. 1) also develop from the embryonic pallium (Puelles et al., 2000; Swanson, 2000; see also Holmgren, 1925).

The DVR (the nidopallium, arcopallium, and mesopallium) occupies a large part of the avian telencephalon and is not organized in a laminar fashion. With a cursory glance, no such huge nuclear structure is recognizable in the mammalian pallium. Nevertheless, the avian DVR and hyperpallium are considered to be pallial since they show important characteristics similar to the mammalian pallium - neocortex, claustrum, and amygdala - in terms of anatomy and function (Karten, 1969; Puelles et al., 2000; Reiner et al., 1998).

Anatomical characteristics: There has been a voluminous amount of hodological studies since the 1960s that showed that the connection patterns of the avian DVR and hyperpallium are similar to the mammalian pallium (Shimizu, 2001). The sensory pathways connecting the thalamus and telencephalon have especially been studied extensively. These studies demonstrated that distinct cell groups in the DVR (the nidopallium, in particular) and hyperpallium receive massive afferent projections from visual, auditory, somatosensory, and related nuclei in the dorsal thalamus. This pattern of projections is similar to the pattern in the mammalian brain, in which distinct modality-specific regions within the pallium (the neocortex, in particular) receive different sensory projections from the dorsal thalamic nuclei (Karten, 1969; Karten \& Shimizu, 1989; Shimizu \& Bowers, 1999). In the avian brain, these primary sensory areas then send projections to multiple nuclei in the telencephalon to form closely interconnected circuits for further processing (Doupe \& Kuhl, 1999; Husband \& Shimizu, 1999). As for motor output from the telencephalon, both the DVR (the arcopallium, in particular) and hyperpallium give rise to long descending efferent projections to motor nuclei in the brainstem and spinal cord. The projection pattern is reminiscent of the cortico-bulbar and cortico-spinal pathways from the mammalian neocortex (Wild \& Williams, 2000; Zeir \& Karten, 1971). Embryological and developmental molecular studies also show similarities between the mammalian and avian pallia (Puelles et al., 2000; Smith-Fernandez et al., 1998). During embryogenesis, pallial-specific transcription factors, such as EMX1, PAX6, and TBR1, are present in the DVR and hyperpallium, which is also true for the mammalian pallium.

Functional characteristics: In mammals, the neocortex plays an essential role in a variety of activities, including sensation, perception, motor control, and cognition. Simi- larly, the avian pallium is crucially involved in sensory processing, such as visual analysis (Bischof \& Watanabe, 1997; Hodos, 1993; Patton, Husband, \& Shimizu, 2008) and auditory analysis (Jarvis, Mello, \& Nottebohm, 1995; Mello \& Clayton, 1994) according to behavioral, physiological, and gene expression studies. There are also ample data showing that these regions are important for the production of highly complex behavior, such as learning, memory, and attention (Güntürkün \& Durstewitz, 2001; Horn, 1985; Iwaniuk \& Hurd, 2005; Knudsen, 2002; Lefebvre, Reader, \& Sol, 2004; Mello, 2002; Nottebohm, Stokes, \& Leonard, 1976; Sadananda, Korte, \& Bischof, 2007; Scharff \& Nottebohm, 1991; Shimizu \& Hodos, 1989). For instance, songbirds have distinct neural circuits in the pallium (and basal ganglia) to learn and produce species-specific songs for communication (Nottebohm et al., 1976). Several pallial structures are directly involved in filial imprinting learning of precocial birds (e.g., ducks and chickens) (Horn, 1985) and sexual imprinting of finches (Rollenhagen \& Bischof, 2000). The caudolateral nucleus of the nidopallium has been compared to the mammalian prefrontal cortex (Güntürkün \& Durstewitz, 2001). Behavioral and physiological studies show that this nucleus plays a major role in working memory, which is used to store and manipulate information for a short time period to achieve behavioral goals. The size of the DVR appears to be larger in some avian species, such as crows and parrots (Iwaniuk \& Hurd, 2005; Lefebvre et al., 2004), which may be related to their ability to exhibit complex behavior more frequently than other birds (Emery, 2006; Hunt, 1996; Pepperburg, 1999).

\section{What is the nuclear pallium (DVR) homologous to in the mammalian pallium?}

The terms hyperpallium, mesopallium, nidopallium, and arcopallium exist only in the avian brain nomenclature, and no other animals have such structures with the same names. During the development of the new nomenclature, some specific names for mammalian pallial structures (e.g., cortex, neocortex) were intentionally avoided for use with the avian DVR. This is because the participants of the 2002 Forum could not reach a consensus about which specific structures of the mammalian pallium (i.e., neocortex, claustrum, or amygdala) correspond to the avian pallium. There are diverse hypotheses regarding the homology of the DVR with the mammalian pallium (Bruce \& Neary, 1995; Butler, 1994; Karten 1969, 1991; Karten \& Shimizu, 1989; Northcutt \& Kaas, 1995; Puelles et al., 2000; Reiner, 1991; Reiner, Yamamoto, \& Karten, 2005; Striedter, 1997). The two main hypotheses will be presented next. In these hypotheses, the DVR is compared to either the neocortex or the claustrum/ amygdala of the mammalian pallium.

Neocortex: One possibility is that some neurons in the 
avian DVR correspond to those in the mammalian neocortex. Massive thalamo-nidopallial projections are similar to the connection patterns of the thalamo-neocortex in mammals, and subsequent intrinsic circuits within the avian DVR (i.e., nidopallium, mesopallium, and arcopallium) are similar to those between layers in the neocortex (Karten 1969, 1991; Karten \& Shimizu, 1989). This hypothesis proposes that some neurons of individual cell populations in the DVR are equivalent to neurons in different layers of the mammalian neocortex, despite the lack of a laminar organization of the DVR as a whole. Several gene expression studies are consistent with this hypothesis. For instance, certain genes (the steroid transcription factor ROR- $\beta$ and the potassium channel EAG2) are expressed in neurons of layer IV of the mammalian neocortex that receives thalamic input. Some of the same genes are also found in specific regions in the DVR (i.e., the entopallium and Field L) which receive projections from the sensory thalamic nuclei (Dugas-Ford \& Ragsdale, 2003). Several other researchers have supported and modified this hypothesis (e.g., Butler, 1994; Reiner, 1991; Reiner et al., 2005).

Claustrum/Amygdala: It is also possible that neurons of the avian DVR are equivalent to those in non-laminar portions of the mammalian pallium - the claustrum and amygdala in particular. The claustrum is a thin sheet of grey matter lying between the outer surface of the basal ganglia and the inner surface of the lateral portion of the neocortex (Fig. 1). It is found in marsupials and placental mammals (Butler, Molnár, \& Manger, 2002) and some monotremes (Ashwell, Hardman, \& Paxinos, 2004). The mammalian amygdala is located in the tip of the temporal lobe and consists of multiple distinct subdivisions including pallial (lateral anterior and basolateral nuclei) and subpallial portions (Swanson \& Petrovich, 1998). The claustrum and pallial amygdala have been compared to the avian DVR based on nuclear appearance, lateral location, and connection patterns with the thalamus and brainstem nuclei (Bruce \& Neary, 1995; Striedter, 1997). Based on developmental expression of homeobox genes (EMX1 and PAX6), the nidopallium is suggested to correspond to the mammalian ventral claustrum and lateral anterior amygdala, whereas the mesopallium corresponds to the dorsal claustrum and basolateral amygdala (Puelles et al., 2000).

Neither hypothesis seems to be flawless since either does not satisfactorily explain all anatomical data available today. Subsequent gene expression studies also revealed evidence against each of these two hypotheses (Gorski et al., 2002; Haesler et al., 2004). Some authors ponder the possibility that the two hypotheses may not be mutually exclusive. Butler and Molnár proposed an alternative hypothesis that the avian DVR is homologous to both the mammalian neocortex and claustrum/amygdala as derivatives of a common embryonic field (Butler \& Molnár, 2002; Molnár \& Butler, 2002).
Further studies about both the avian and mammalian pallial structures are clearly warranted to clarify the nature of the DVR and to identify the mammalian counterpart. The avian DVR is a large and heterogeneous structure containing sensory-specific and non-sensory regions. Certainly, more anatomical and functional information is needed about the non-sensory regions, which have been scarcely studied compared to the regions directly associated with sensory processing. In the mammalian pallium, almost nothing is known about the function of the claustrum which has been suggested to be involved in the generation and control of consciousness (Crick \& Koch, 2005).

\section{How does the revised view of the avian brain explain the cognitive abilities of birds?}

Almost daily, new information is learned about the complex behavior of non-human animals - behavior that was traditionally considered to be uniquely human. Novel discoveries of animal cognition are no longer surprising because they are consistent with the modern, revised interpretations of the vertebrate brain.

In the particular case of birds, the modern view of the avian brain provides several insights regarding their highly sophisticated behavior and underlying neural systems. First, the revised view supports the assumption that the existence of a developed higher brain structure - the pallium - is directly related to the production of flexible, learned, and complex behavior. The cognitive abilities of birds are difficult to explain from the mammalian-centric classic view of the vertebrate brain evolution. This is because avian (and other non-mammalian) brains were believed to lack the sufficient hardware (a large laminated pallium or neocortex) necessary to carry out complex behavior. The modern interpretation states that the avian nuclear pallium is as anatomically developed and as functionally sophisticated as the mammalian laminar pallium. Indeed, of all living vertebrates, birds and mammals have proportionally large telencephalons compared to any other animals due to the enlarged pallial region of each (Northcutt, 1981). It is reasonable to assume that as the avian pallium became enlarged and elaborated, despite its non-laminated configuration, birds evolved to perform remarkably complex behavior.

Second, an important insight resulting from the modern view is that the evolutionary origins of the complex behavior of birds and mammals are most likely different. In other words, birds and mammals independently evolved with elaborated neural systems to generate similarly complex behavior (Emery, 2006; Shimizu, 2001, 2007). The convincing evidence to support this argument is that the developments of the avian and mammalian pallia were separate (yet parallel) events in evolution. According to endocasts of extinct animals, stem amniotes (the common ancestor of 
reptiles, birds, and mammals) in the Early Carboniferous period had only a slender, elongated forebrain with no signs of the pallial enlargement found in living birds and mammals (Hopson, 1979; Ulinski, 1983). In the lineage leading mammals, endocasts of early synapsids show that their forebrain remained diminutive. Only early mammals of the Jurassic period started to show an enlarged forebrain, which was most likely correlated with the development of the cerebral cortex. A gradual, but not necessarily impressive, expansion of the reptilian forebrain was seen in the Late Triassic period. The forebrain became substantially enlarged only when birds emerged, suggesting that the significant development of the nuclear DVR occurred during the reptile-bird transition. These observations about the distinct and separate evolutions of the pallia in birds and mammals suggest that their complex behaviors (as products of the enlarged and elaborated pallia) also have distinct and separate evolutionary origins (Shimizu, 2001, 2007).

Finally, the modern view raises a question regarding the indispensability of the laminated neural architecture for the generation of complex behavior. In humans and other mammals, a six-layered neocortex seems essential to accomplish complex behavior, and thus a lamination is often presumed to be the most optimal design for sophisticated neural computation. It is easy to refute this assertion since not all mammals appear to exhibit complex behavior, whereas many birds show such behavior without a six-layered neocortex. The presence of a six-layered neocortex does not guarantee the generation of behavioral complexity, which can be achieved by an alternative design - a nuclear pallium (DVR). In fact, the interconnections among specific brain structures may be more important than the presence of a tightly layered architecture (Jarvis et al., 2004; Shimizu, 2001, 2007). I hasten to state that this argument is not meant to underestimate the advantage of a laminar organization. The lamination is probably one of the most efficient designs to process topographically mapped information. All vertebrates, including non-mammals, have many laminated brain structures, such as olfactory bulb, retina, and midbrain. The avian optic tectum of the midbrain is particularly large and differentiated. Although the tectum appears to be less directly involved in cognitive proficiencies and complex behavior compared to the pallium, the tectum and DVR have close anatomical and functional connections with each other (Shimizu, 2001, 2007).

\section{Why can birds be so smart?}

In other words, how is it possible for birds to behave in surprisingly intricate and flexible ways? The modern view of brain evolution provides a proximate explanation. In short, birds, like mammals, have developed a high-level forebrain structure - an enlarged and elaborated pallium - that is nec- essary to support such remarkable behavior. The caveat is that the avian pallium and mammalian counterpart are markedly different in terms of the architectural organization of neurons (i.e., nuclear vs. laminar). Although both types of pallium are capable of generating behavioral complexity, the exact significance of the anatomical differences on the underlying cognitive processes remains vastly unexplored (Butler \& Cortterill, 2006; Güntürükün \& Durstewitz, 2001; Shimizu \& Bowers, 1999). Even when birds and mammals exhibit similarly complex behavior, it is possible that the DVR and neocortex involve qualitatively dissimilar computational principles and mechanisms to generate such behavior. Without more information about the two types of pallial organization, it is still presumptuous to assume that the superficial similarity of behavior between birds and mammals is attributable to an essentially identical kind of underlying process.

\section{Concluding Question}

\section{What are the main lessons that comparative cognitive and behavioral researchers can learn from the history of com- parative neuroscience?}

Perhaps the important lesson for researchers of animal cognition and behavior is that the true nature of vertebrate evolution - divergence and multi-linearity - needs to be adamantly reasserted in the course of comparative investigations. Researchers should resist the temptation to fall back on the familiar scala naturae-based views. The mammaliancentric or anthropomorphic perspective, which has persistently permeated comparative research despite the scientific evidence, must be avoided (Campbell \& Hodos, 1991; Hodos \& Campbell, 1969; Wynne, 2007). The early comparative neuroanatomists who subscribed to such an assumption unintentionally set in motion the misguided nomenclature that lasted about 100 years. With this lesson from comparative neuroscience in mind, the cognition and behavior of animals should be evaluated within the framework of the multi-linear evolution, and not on the basis of an ascending continuum toward mammals and humans. The complex cognitive and behavioral abilities of birds which have enabled their successful adaptation to the environment should be appreciated in their own right, not because they resemble some aspects of human behavior and cognition. The "bird brain" - despite the rather insulting colloquial connotation of the term - is a truly unique exceptional machine deserving of our respect.

\section{References}

Ariëns Kappers, C.U., Huber, C.G. \& Crosby, E.C. (1960). Comparative Anatomy of the Nervous System of Vertebrates, Including Man. (Original work published 1936). 
New York: Hafner.

Ashwell, K.W., Hardman, C., \& Paxinos, G. (2004). The Claustrum is not missing from all monotreme brains. Brain Behavior \& Evolution, 64, 223-241.

Bingman, V.P. \& Able, K.P. (2002). Maps in birds: representational mechanisms and neural bases. Current Opinion in Neurobiology, 12, 745-750.

Bischof, H.J. \& Watanabe, S. (1997). On the structure and function of the tectofugal visual pathway in laterally eyed birds. European Journal of Morphology, 35, 246-254.

Bruce, L.L. \& Neary, T.J. (1995). The limbic system of tetrapods: a comparative analysis of cortical and amygdalar populations. Brain Behavior and Evolution, 46, 224-234.

Butler, A.B. (1994). The evolution of the dorsal pallium in the telencephalon of amniotes: cladistic analysis and a new hypothesis. Brain Research Review, 19, 66-101.

Butler, A.B. \& Cortterill, R.M. (2006). Mammalian and avian neuroanatomy and the question of consciousness in birds. Biological Bulletin, 211, 106-127.

Butler, A.B. \& Hodos, W. (2005). Comparative vertebrate neuroanatomy: Evolution and adaptation, 2nd edition. Hoboken: New Jersey: Wiley-Liss.

Butler, A.B. \& Molnár, Z. (2002). Development and evolution of the collopallium in amniotes: a new hypothesis of field homology. Brain Research Bulletin, 57, 475-479.

Butler, A.B., Molnár, Z., \& Manger, P.R. (2002). Apparent absence of claustrum in monotremes: implications for forebrain evolution in amniotes. Brain Behavior and Evolution, 60, 230-240.

Campbell, C.B.G. \& Hodos, W. (1991). The scala naturae revisited: Evolutionary scales and anagenesis in comparative psychology. Journal of Comparative Psychology, 3, 211-221.

Carroll, R.L. (1988). Vertebrate paleontology and evolution. New York: W.H. Freeman.

Clayton, N.S. \& Dickinson, A. (1998). Episodic-like memory during cache recovery by scrub jays. Nature, 395, 272-274.

Clayton, N.S., Bussey, T.J., \& Dickinson, A. (2003). Can animals recall the past and plan for the future? Nature Review Neuroscience, 4, 685-691.

Cook, R.G., Levison, D.G., Gillett, S.R., \& Blaisdell, A.P. (2005). Capacity and limits of associative memory in pigeons. Psychonomic Bulletin \& Review, 12, 350-358.

Doupe, A.J. \& Kuhl, P.K. (1999). Bird and human speech: common themes and mechanisms. Annual Review of Neuroscience, 22, 567-631.

Dugas-Ford, J. \& Ragsdale, C. (2003). Some nuclei in chick dorsal telencephalon have molecular signatures of layer 4 of the mammalian cerebral cortex. Brain Behavior and Evolution, 62, 170

Edinger, L. (1908). The relations of comparative anatomy to comparative psychology. Comp. Neurol. Psychol., 18,
437-457.

Edinger, L., Wallenberg, A., \& Holmes G.M. (1903). Untersuchungen über die vergleichende Anatomie des Gehirns. 3. Das Vorderhirn der Vögel. Abhand Senekenberate Gesellsch., Frankfurt Am Main, 20, 343-426.

Emery, N.J. (2006). Cognitive ornithology: the evolution of avian intelligence. Philosophical Transactions of the Royal Society B: Biological Sciences, 361, 23-43.;

Gentner, T.Q., Fenn, K.M., Margoliash, D., \& Nusbaum, H.C. (2006). Recursive syntactic pattern learning by songbirds. Nature, 440, 1204-1207.

Gorski, J.A., Talley, T., Qiu, M., Puelles, L., Rubenstein, J.L. \& Jones, K.R. (2002). Cortical excitatory neurons and glia, but not GABAergic neurons, are produced in the Emx1-expressing lineage. Journal of Neuroscience, 22, 6309-6314.

Güntürükün, O. \& Durstewitz, D. (2001). Multimodal areas of the avian forebrain - blueprints for cognition? In: Roth, G., Wulliman, M.F. (Eds.), Brain evolution and cognition (pp. 431-450). New York: Wiley/Spektrum..

Haesler, S., Wada, K., Nshdejan, A., Morrisey, E.E., Lints, T., Jarvis, E.D., \& Scharff, C. (2004). FoxP2 expression in avian vocal learners and non-learners. Journal of Neuroscience, 24, 3164-3175.

Herrick, C.J. (1956). The evolution of human nature. Austin: University of Texas Press.

Hodos, W. (1993). The visual capabilities of birds. In: Zeigler, H.P., Bischof, H.-J. (Eds.), Vision, brain, and behavior in birds (pp. 77-98). Cambridge, Massachusetts: MIT Press.

Hodos, W. \& Campbell, C.B.G. (1969). Scala naturae: why there is no theory in comparative psychology. Psychological Review, 76, 337-350.

Holmgren, N. (1925). Points of view concerning forebrain morphology in higher vertebrates. Acta. Zool. Stockh., 6, 413-477.

Hopson, J.A. (1979). Paleoneurology. In: Gans, C., Northcutt, R.G., Ulinski, P. (Eds.), Biology of the Reptilia, vol. 9, (pp. 39-146). New York: Academic Press.

Horn, G. (1985). Memory, imprinting, and the brain. New York: Oxford University Press.

Hunt, G.R. (1996). Manufacture and use of hook-tools by New Caledonian crows. Nature, 379, 249-251.

Husband, S. \& Shimizu, T. (1999). Efferent projections of the ectostriatum in pigeons (Columba livia). Journal of Comparative Neurology, 406, 329-345.

Iwaniuk, A.N. \& Hurd, P.L. (2005). The evolution of cerebrotypes in birds. Brain Behavior and Evolution, 65, 215-230.

Jarvis, E. D., Güntürkün, O., Bruce, L., Csillag, A., Karten, H. J., Kuenzel, W., Medina, L., Paxinos, G., Perkel, D. J., Shimizu, T., Striedter, G. F., Wild, J. M., Ball, G. F., Douglas-Ford, J., Durand, S., Hough, G., Husband, S., Ku- 
bikova, L., Lee, D. W., Mello, C. V., Powers, A., Siang, C., Smulders, T. V., Wada, K., White, S. A., Yamamoto, K., Yu, J., Reiner, A., \& Butler, A. B. (2005). Avian brains and a new understanding of vertebrate brain evolution. Nature Reviews Neuroscience, 6, 151-159.

Jarvis, E.D., Ribeiro, S., da Silva, M.L., Ventura, D., Vielliard, J., \& Mello, C.V. (2000). Behaviourally driven gene expression reveals song nuclei in hummingbird brain. $\mathrm{Na}$ ture, 406, 628-632.

Jarvis, E.D., Mello, C.V., \& Nottebohm, F. (1995). Associative learning and stimulus novelty influence the song-induced expression of an immediate early gene in the canary forebrain. Learning \& Memory, 2, 62-80.

Juorio, A.V. \& Vogt, M. (1967). Monoamines and their metabolites in the avian brain. Journal of Physiology, 189, 489-518.

Källén, B. (1953). On the nuclear differentiation during embryogenesis in the avian forebrain and some notes on the amniote strio-amygdaloid complex. Avata Anat ( $\mathrm{Ba}$ sel), 17, 72-84.

Karten, H.J. (1969). The organization of the avian telencephalon and some speculations on the phylogeny of the amniote telencephalon. Annals of the New York Academy of Sciences, 167, 164-179.

Karten, H.J. (1991). Homology and evolutionary origins of the 'neocortex'. Brain Behavior and Evolution, 38, 264272.

Karten, H.J. \& Dubbeldam, J.L. (1973). The organization and projections of the paleostriatal complex in the pigeon (Columba livia). Journal of Comparative Neurology, 148, 61-90.

Karten, H.J. \& Hodos, W. (1967). A Stereotaxic Atlas of the Brain of the Pigeon (Columba livia). Baltimore, Maryland: The Johns Hopkins University Press.

Karten, H.J. \& Shimizu, T. (1989). The origins of neocortex: Connections and lamination as distinct events in evolution. Journal of Cognitive Neuroscience, 1, 291-301.

Kitt, C.A. \& Brauth, S.E. (1986a). Telencephalic projections from midbrain and isthmal cell groups in the pigeon. I. Locus coeruleus and subcoeruleus. Journal of Comparative Neurology, 247, 69-91.

Kitt, C.A. \& Brauth, S.E. (1986b). Telencephalic projections from midbrain and isthmal cell groups in the pigeon. II. The nigral complex. Journal of Comparative Neurology, 247, 92-110.

Knudsen, E.I. (2002). Instructed learning in the auditory localization pathway of the barn owl. Nature, 417, 322-328.

Kuenzel, W.J. \& Masson, M. (1988). A Stereotaxic Atlas of the Brain of the Chick (Gallus domesticus). Baltimore, Maryland: The Johns Hopkins University Press.

Kuhlenbeck, H. (1938). The ontogenetic development and phylogenetic significance of the cortex telencephali in the chick. Journal of Comparative Neurology, 69, 273-301.
Lefebvre, L., Reader, S.M., \& Sol, D. (2004). Brains, innovations and evolution in birds and primates. Brain, Behavior, and Evolution, 63, 233-246.

Lloyd Morgan, C. (1894). An introduction to comparative psychology. New York: Scribner.

Marin, O. \& Rubenstein, J.L. (2001). A long, remarkable journey: tangential migration in the telencephalon. $\mathrm{Na}$ ture Review Neuroscience, 2, 780-790.

Mello, C.V. (2002). Mapping vocal communication pathways in birds with inducible gene expression. Journal of Comparative Physiology A, 188, 943-959.

Mello, C.V. \& Clayton, D.F. (1994). Song-induced ZENK gene expression in auditory pathways of songbird brain and its relation to the song control system. Journal of Neuroscience, 14, 6652-6666.

Molnár, Z. \& Butler, A.B. (2002). Neuronal changes during forebrain evolution in amniotes: an evolutionary developmental perspective. Progress in Brain Research, 136, 21-38.

Northcutt, R.G. (1981). Evolution of the telencephalon in nonmammals. Annual Reviews of Neuroscience, 4, 301350 .

Northcutt, R.G. \& Kaas, J.H. (1995). The emergence and evolution of mammalian neocortex. Trends in Neurosciences, 18, 373-379.

Nottebohm, F. (2002). Neuronal replacement in adult brain. Brain Research Bulletin, 57, 737-749.

Patton, T. B., Husband, S. A., \& Shimizu, T. (2008). Female stimuli trigger gene expression in male pigeons. Social Neuroscience, Mar 6, 1-12.

Pepperberg, I. (1999). The Alex Studies: Cognitive and Communicative Abilities of Grey Parrots. Cambridge, Massachusetts: Harvard University Press.

Puelles, L., Kuwana, E., Puelles, E., Bulfone, A., Shimamura, K., Keleher, J., Smiga, S. \& Rubenstein, J. (2000). Pallial and subpallial derivatives in the embryonic chick and mouse telencephalon, traced by the expression of the genes Dlx-2, Emx-1, Nkx-2.1, Pax-6, and Tbr-1. Journal of Comparative Neurology, 424, 409-438.

Reiner, A., Brauth, S.E., \& Karten, H.J. (1984). Evolution of the amniote basal ganglia. Trends in Neurosciences, 7 , 320-325.

Reiner, A., Medina, L., \& Veenman, C.L. (1998). Structural and functional evolution of the basal ganglia in vertebrates. Brain Research Review, 28, 235-285.

Reiner, A., Perkel, D.J., Bruce, L., Butler, A. B., Csillag, A., Kuenzel, W., Medina, L., Paxinos, G., Powers, A., Shimizu, T., Striedter, G.F., Wild, J.M., Ball, G.F., Durand, S., Güntürkün, O., Lee, D.W., Mello, C.V., Powers, A., White, S.A., Hough, G., Kubikova, L., Smulders, T.V., Wada, K., Douglas-Ford, J., Husband, S., Yamamoto, K., Yu, J., Siang, C., \& Jarvis, E.D. (2004). Revised nomenclature for avian telencephalon and some related brainstem 
nuclei. Journal of Comparative Neurology, 473, 377-414.

Reiner, A., Yamamoto, K., \& Karten, H.J. (2005). Organization and evolution of the avian forebrain. Anatomical Record, 287A, 1080-1102.

Rollenhagen, A. \& Bischof, H.J. (2000). Evidence for the involvement of two areas of the zebra finch forebrain in sexual imprinting, Neurobiology of Learning and Memory, 73, 101-113.

Romanes, G.J. (1882). Animal intelligence. New York: Appleton.

Rose, M. (1914). Über die cytoarchitektonische Gliederung des Vorderhirns der Vogel. J. f. Psychol. Neurol., 21 (suppl. 1), 278-352.

Sadananda, M., Korte, S., \& Bischof, H.J. (2007). Afferentation of a caudal forebrain area activated during courtship behavior: a tracing study in the zebra finch (Taeniopygia guttata). Brain Research, 1184, 108-120

Scharff, C. \& Nottebohm, F. (1991). A comparative study of the behavioral deficits following lesions of various parts of the zebra finch song system: implications for vocal learning. Journal of Neuroscience, 11, 2896-2913.

Shimizu, T. (2001). Evolution of the forebrain in tetrapods. In: Roth, G., Wulliman, M.F. (Eds.), Brain evolution and cognition (pp. 135-184). New York, Wiley/Spektrum,

Shimizu, T. (2007). The avian brain revisited: Anatomy and evolution of the telencephalon. In S. Watanabe \& M. A. Hofman (Eds.), Integration of Comparative Neuroanatomy and Cognition (pp. 55 - 73). Tokyo: Keio University Press.

Shimizu, T. \& Bowers, A.N. (1999). Visual pathways in the avian telencephalon: Evolutionary implications. Behavioural Brain Research, 98, 183-191.

Shimizu, T. \& Hodos, W. (1989). Reversal learning in pigeons: Effects of selective lesions of the Wulst. Behavioral Neuroscience, 103, 262-273.

Smith-Fernandez, A., Pieau, C., Reperant, J., Boncinelli, E., \& Wassef, M. (1998). Expression of the Emx-1 and Dlx1 homeobox genes define three molecularly distinct domains in the telencephalon of mouse, chick, turtle and frog embryos: implications for the evolution of telencephalic subdivisions in amniotes. Development, 125, 2099-2111.

Stokes T.M., Leonard, C.M., \& Nottebohm, F. (1974). The telencephalon, diencephalon, and mesencephalon of the canary, Serinus canaria, in stereotaxic coordinates. Journal of Comparative Neurology, 156, 337-374.

Striedter, G.F. (2004). Principles of Brain Evolution. Sunderland, Massachusetts: Sinuaer Associates.

Swanson, L.W. \& Petrovich, G.D. (1998). What is the amygdala? Trends in Neurosciences, 21, 323-331.

Swanson, L.W. (2000). What is the brain? Trends in Neurosciences, 23, 519-527.

Thanos, S. \& Mey, J. (2001). Development of the visual system of the chick. II. Mechanisms of axonal guidance.
Brain Research Review, 5, 205-245.

Ulinski, P.S. (1983). Dorsal Ventricular Ridge. A Treatise on forebrain organization in reptiles and birds. New York: John Wiley.

Wasserman E.A. \& Zentall, T.R. (2006). Comparative cognition. Experimental explorations of animal intelligence. New York: Oxford.

Watanabe, S. \& Hofman, M. A. (Eds.). (2008). Integration of Comparative Neuroanatomy and Cognition. Tokyo, Keio University Press.

Watanabe, S., Sakamoto, J., \& Wakita, M. (1995). Pigeons' discrimination of paintings by Monet and Picasso. Journal of the Experimental Analysis of Behavior, 63, 165-174.

Wild, J.M. \& Williams, M.N. (2000). Rostral wulst in passerine birds. I. Origin, course, and terminations of an avian pyramidal tract. Journal of Comparative Neurology, 416, 429-450.

Wynne, C.D. (2007). What are animals? Why anthropomorphism is still not a scientific approach to behavior. Comparative Cognition \& Behavior Reviews, 2, 125-135.

Zeigler, H.P. \& Bischof, H.-J. (Eds.). (1993). Vision, brain, and behavior in Birds. Cambridge, Massachusetts: MIT Press.

Zeigler, H.P. \& Marler, P. (Eds.). (2008). Neuroscience of birdsong. Cambridge, Massachusetts: MIT Press.

Zeir, H., \& Karten, H.J. (1971). The archistriatum of the pigeon: Organization of afferent and efferent connections. Brain Research, 31, 313-326. 